\title{
Obesity measures in the Kiribati population: a need to reclassify body mass index cut- points
}

\author{
P. E. Eme ${ }^{*^{*}}$ D, B. Burlingame², N. D. Kim², S. Foliaki ${ }^{3}$, C. Wham ${ }^{4}$ and J. Douwes ${ }^{3}$
}

\begin{abstract}
Background: Obesity is a public health problem in Micronesia. The objective of the study was to assess obesity, the relationship between body mass index (BMI) and body fat percentage (BF\%) among adults, and determine the appropriate BMI cut-points in Kiribati.

Methods: A cross-sectional study was undertaken among 483 adults randomly selected from South Tarawa (ST) and Butaritari (BT). Weight, height, BF\% and physical activity level (PAL) was measured using standard methods. Linear and quadratic regression analyses were conducted to assess the association between BF\% and BMI whilst controlling for age and gender. Receiver operating characteristics (ROC) curve analyses were used to assess whether for the Kiribati population alternative BMI cut-off points for obesity are needed.

Results: Approximately $75 \%$ of participants were obese using standard BMI and BF\% cut-offs, with the highest prevalence observed in South Tarawa. BF\% was significantly $(p<0.001)$ and positively associated with age (males, $r=0.78$; females, $r=0.67 ; p<0.001$ ) and BMI. Based on ROC-curve analyses the BMI cut-offs for predicting high BF\% among I-Kiribati people were $24.5 \mathrm{~kg} / \mathrm{m}^{2}$ for males and $32.9 \mathrm{~kg} / \mathrm{m}^{2}$ for females.

Conclusions: In conclusion, the majority of adults in Kiribati were either obese or overweight and had high BF\%. We suggest that ethnic-specific BMI cut-points to define obesity for the population of Kiribati may be more appropriate than the currently used international cut-points.
\end{abstract}

Keywords: Body mass index, Body fat percent, Relationship, Predictor, Adults, Kiribati

\section{Background}

The prevalence of overweight and obesity has increased considerably in the past few decades, and has become a significant public health problem globally, with current estimates indicating that 600 million adults are obese and 1.9 billion are overweight [1]. Adult obesity prevalence in Pacific Small Island Developing State (PSIDS), including Nauru (61\%), Fiji (30\%) and Vanuatu (24\%) are among the highest in the world [2]. This is true also

\footnotetext{
* Correspondence: paul.eze@unn.edu.ng

1 Department of Nutrition and Dietetics, University of Nigeria, Nsukka, Enugu State, Nigeria

Full list of author information is available at the end of the article
}

for Micronesia, a subregion of Oceania, composed of thousands of small Islands in the western Pacific Ocean, including Kiribati [3]. These Islands mainly rely on the United States for development aid for implementation, acceleration and scaling up of nutrition programmes and policies. However, the sharp increase in obesity rates in this region over the past 40 years shows that current efforts are insufficient to kerb the obesity epidemic [4]. In fact, in 2016, the mean obesity prevalence for adult males and females in Kiribati was $46 \%$, a significant increase from $32.2 \%$ in 1997 , representing an average annual growth rate of $1.96 \%$ [5].

(c) The Author(s). 2020 Open Access This article is licensed under a Creative Commons Attribution 4.0 International License, which permits use, sharing, adaptation, distribution and reproduction in any medium or format, as long as you give appropriate credit to the original author(s) and the source, provide a link to the Creative Commons licence, and indicate if changes were made. The images or other third party material in this article are included in the article's Creative Commons licence, unless indicated otherwise in a credit line to the material. If material is not included in the article's Creative Commons licence and your intended use is not permitted by statutory regulation or exceeds the permitted use, you will need to obtain permission directly from the copyright holder. To view a copy of this licence, visit http://creativecommons.org/licenses/by/4.0/ The Creative Commons Public Domain Dedication waiver (http://creativecommons.org/publicdomain/zero/1.0/) applies to the data made available in this article, unless otherwise stated in a credit line to the data. 
Many studies have shown that obesity, especially central body fatness, is linked with increased risk of morbidity and mortality. In particular, it has been associated with risk factors for coronary heart disease including type 2 diabetes, insulin resistance, and hypertension; cancer; sleep disorders; and anxiety [6, 7]. A significant decrease in physical activity levels and energy expenditure, combined with an increase in energy intake are the main factors contributing to obesity [8].

There are many methods to assess adiposity including measurements of waist circumference, waist-hip ratio, waist-to-height ratio, skinfold calliper measurements, body mass index (BMI), bioelectrical impedance analysis (BIA), under-water weighing (densitometry), near infrared reactance (NIR), magnetic resonance imaging (MRI) and dual-energy X-ray absorptiometry (DEXA) [9]. BMI is inexpensive, relatively easy to calculate and therefore most commonly used, but it does not distinguish between fat and lean body mass. The World Health Organization (WHO) recommends BMI as the most useful populationlevel measure of overweight and obesity (independent of sex and age), and cut-offs of $>25 \mathrm{~kg} / \mathrm{m}^{2}$ and $>30 \mathrm{~kg} / \mathrm{m}^{2}$ are now commonly applied as a definition of overweight and obese, respectively [10]. Body impedance analysis (BIA), a relatively simple, quick, affordable, non-invasive, and reliable body composition method, is widely used to measure percentage body fat (BF\%), but is dependent on height and cannot be evaluated independently from fat free mass $[11,12]$. The validity of BIA has previously been established for different ethnic groups [13, 14].

Previous studies found a significant positive association between BMI and BF (\%) [15-17]. However, the majority of studies were conducted in high-income countries, with only few studies from low-income countries and none from the Pacific region [13, 14]. As a consequence, results from previous studies may not be generalizable to other ethnic populations.

In this study, we aimed to answer the following questions: "what are the adult obesity rates in South Tarawa and Butaritari using different measures?", and "are the WHO BMI cut-points to defined obesity valid for the IKiribati population?" To address these questions we measured, in a sub-population of Pacific Island adults from two atoll Kiribati Islands (one predominantly urban and the other rural), the prevalence of adiposity, and assessed the association between BMI and BF\% (using BIA) whilst taking into account age and sex.

\section{Methods}

\section{Study area}

South Tarawa (ST) is the capital of the Republic of Kiribati and is predominantly urban. It is home to about half of the total Kiribati population and most of the government, commercial and education facilities. Butaritari (BT) is the second most northerly of the Gilbert Islands, formerly called Makin Atoll by the US Military, and is rural with a population of 4346 people inhabiting 12 villages [18].

\section{Participants and design}

This was a cross-sectional survey of a household-based sample of adults aged $\geq 18$ years using a multi-stage sampling technique. A total sample of 483 adults (171 from ST and 312 from BT) were recruited using a systematic random sampling method. In particular, in each location, every third house at each site was approached and invited to participate in the study. The inclusion criterion was any household with a mother and father and one or more children living and eating in the same household. All pregnant women and adults who were chronically sick and bedridden were excluded. The respondents were mostly adult (18 years of age) who were household heads and/or those who were involved in the cooking/purchasing of the foods.

Ethical approval was obtained from the Massey University Research Ethics Committee (No: 4000018013). We also obtained a research permit from Kiribati Immigration (RP No- 14/2017). Written consent was obtained from each participant, and data was collected by locally trained research assistants, which took place from $\mathrm{Au}$ gust to September, 2018.

\section{BMI and body fat percentage (BF\%)}

Height was measured using a height metre and was recorded to the nearest $0.1 \mathrm{~cm}$. Measurements were taken with the subjects bare footed, standing erect with feet parallel, and heels put together in line with methods described by Jellife [19]. Weight (in $\mathrm{kg}$ ) was measured using a calibrated electronic scale with digital readout (seca 808, Germany) to the nearest $0.1 \mathrm{~kg}$. BMI [weight/ height ${ }^{2}$ ] was used to classify underweight $\left(<18.0 \mathrm{~kg} / \mathrm{m}^{2}\right)$, normal $\left(18-24.99 \mathrm{~kg} / \mathrm{m}^{2}\right)$, overweight $\left(25-29.9 \mathrm{~kg} / \mathrm{m}^{2}\right)$, obesity class $1\left(30-34.99 \mathrm{~kg} / \mathrm{m}^{2}\right)$, obesity class II (35$\left.39.99 \mathrm{~kg} / \mathrm{m}^{2}\right)$ and obesity class III $\left(\geq 40.0 \mathrm{~kg} / \mathrm{m}^{2}\right)$ [7]. Body composition measurement (corrected for sex, age and height) was carried out using a single bio-impedance analyser system (BC-549, Tanita Corp, Illinois, USA) as per international guidelines [10]. BF\% was categorised (low, normal, high, very high) using criteria described by Gallagher et al. [20]. All measurements were taken from 9.00-13.00 $\mathrm{h}$ and participants were asked not to engage in vigorous activities $12 \mathrm{~h}$ prior to the measurements.

\section{Physical activity}

The short form of the New Zealand Physical Activity Questionnaire (NZPAQ-SF) was used to assess the duration and frequency of brisk walking, and moderate- and vigorous-intensity activities performed in the last 7 days. The NZPAQ-SF, an adaptation of the International Physical Activity Questionnaire (IPAQ), was validated 
against heart rate monitoring in a multi-ethnic population, including Pacific Islanders, and demonstrated acceptable validity $(r=0.25, p<0.001)$ [21]. Based on frequency (days/week) and average daily duration (min/day) of walking, and moderate and vigorous-intensity activities, metabolic equivalent (MET) values were calculated as follows: METS for walking, moderate- and vigorous-intensity activity (3.3, 4.0, and 8.0, respectively) were multiplied by duration of each activity, summed, and expressed as MET$\mathrm{min} /$ week based on scoring criteria established by the IPAQ Committee for Physical Activity Level (PAL) [22].

\section{Statistical analysis}

All analyses were conducted using SPSS version 20. Linear regression was used to assess associations between $\mathrm{BMI}$ and $\mathrm{BF} \%$. In addition, we conducted quadratic regression to assess whether the association between BMI and $\mathrm{BF} \%$ was predominantly linear or curvilinear, similar to other international studies $[15,16]$. All regression analyses were controlled for age and stratified by sex (unless indicated otherwise). ROC curve analyses were used to assess whether for the Kiribati population alternative BMI cut-off points for obesity may be needed with improved sensitivity (true positive rate) and specificity (true negative rate). $P$-values $\leq 0.05$ were used to indicate statistical significance.

\section{Results}

Table 1 shows the population characteristics. Weight, BF\% and BMI of participants in South Tarawa were significantly $(p<0.05)$ higher than that of participants from Butaritari.

The majority $(>70 \%)$ of participants in both locations had high BF\% and were classified as obese based on BMI results, with again the highest proportion of obesity in South Tarawa.

BMI and age were both consistently and positively associated with BF\% for both males and females (Table 2). PAL was inversely associated with $\mathrm{BF} \%$, but this was statistically significant only in females, and after controlling for other variables this was no longer significant. In multivariate regression (mutually adjusting for all other variables - age, PAL and location) the regression coefficient (RC) of BMI for males increased from 1.21 to 1.49, but in females it decreased from 0.86 to 0.72 .

Visual inspection of the scatter plot (Fig. 1) confirmed the positive association between BF\% and BMI, which appeared linear in nature and curvilinear towards higher $\mathrm{BF} \%$ values. Comparing the explained variance between linear and quadratic regression analyses (see Fig. 1) showed only a slight difference i.e. $95 \%$ versus $96 \%$ in men and $98 \%$ versus $98 \%$ in women, suggesting that the model fit of the quadratic regression model was not necessarily better than that of linear regression models.

Table 1 Population characteristics

\begin{tabular}{|c|c|c|c|c|}
\hline & $\begin{array}{l}\text { South Tarawa } \\
(N=171)\end{array}$ & $\begin{array}{l}\text { Butaritari } \\
(N=312)\end{array}$ & $\begin{array}{l}\text { Total } \\
(N=483)\end{array}$ & $P$-value \\
\hline Age (yrs)(Mean \pm SD) & $40.8 \pm 9.4$ & $40.4 \pm 13.6$ & $40.6 \pm 12.2$ & 0.740 \\
\hline $\mathrm{PAL}($ Mean $\pm \mathrm{SD})$ & $1.5 \pm 0.2$ & $2.5 \pm 1.4$ & $2.2 \pm 1.2$ & $P<0.0001$ \\
\hline Height $(m)$ (Mean \pm SD) & $162.0 \pm 7.3$ & $161.3 \pm 8.2$ & $161.6 \pm 7.9$ & 0.374 \\
\hline Weight (kg) (Mean \pm SD) & $88.6 \pm 17.8$ & $78.5 \pm 15.2$ & $82.1 \pm 16.9$ & $P<0.0001$ \\
\hline Body fat, \% (Mean \pm SD) & $38.4 \pm 7.8$ & $32.3 \pm 11.4$ & $34.5 \pm 10.7$ & $P<0.0001$ \\
\hline Body mass index, $\mathrm{kg} / \mathrm{m}^{2}$ (Mean $\left.\pm \mathrm{SD}\right)$ & $33.7 \pm 6.2$ & $30.4 \pm 6.6$ & $31.6 \pm 6.7$ & $P<0.0001$ \\
\hline Males (\%) & $38(26.0 \%)$ & $108(74.0 \%)$ & $146(30.2 \%)$ & 0.005 \\
\hline Females (\%) & $133(39.5 \%)$ & $204(60.5 \%)$ & $337(69.8 \%)$ & \\
\hline \multicolumn{5}{|l|}{ BF\% Classification (BIA) } \\
\hline Low (\%) & $1(0.6)$ & $2(0.6)$ & $3(1.0)$ & \\
\hline Normal (\%) & $14(8.2)$ & $110(35.3)$ & $124(25.7)$ & $P<0.0001$ \\
\hline High (\%) & $35(20.4)$ & $104(33.3)$ & $137(28.4)$ & \\
\hline Very High (\%) & $121(70.8)$ & $96(30.8)$ & $217(44.9)$ & \\
\hline \multicolumn{5}{|l|}{ Classification of BMI $\left(\mathrm{kg} / \mathrm{m}^{2}\right)$} \\
\hline Underweight (\%) & $1(0.6)$ & - & $1(0.2)$ & \\
\hline Normal (\%) & $6(3.5)$ & $64(20.5)$ & $70(14.5)$ & \\
\hline Overweight (\%) & $36(21.1)$ & $102(32.7)$ & $138(28.6)$ & \\
\hline Obesity Class I (\%) & $50(29.2)$ & $80(25.6)$ & $130(26.9)$ & $P<0.0001$ \\
\hline Obesity Class II (\%) & $39(22.8)$ & $47(15.1)$ & $86(17.8)$ & \\
\hline Obesity Class III (\%) & $39(22.8)$ & $19(6.1)$ & $58(12.0)$ & \\
\hline
\end{tabular}


Table 2 Regression models showing the association between BF\% (dependent variable) and BMI, age, PAL and location (independent variables) stratified for males and females

\begin{tabular}{|c|c|c|c|c|c|c|c|c|}
\hline & \multicolumn{4}{|l|}{ Males } & \multicolumn{4}{|l|}{ Females } \\
\hline & $\begin{array}{l}\text { Unadjusted regression } \\
\text { coefficient }(95 \% \mathrm{CL})\end{array}$ & $\begin{array}{l}P \text { - } \\
\text { value }\end{array}$ & $\begin{array}{l}\text { Adjusted }^{\mathrm{a}} \text { regression } \\
\text { coefficient }(95 \% \mathrm{CL})\end{array}$ & $\begin{array}{l}P \text { - } \\
\text { value }\end{array}$ & $\begin{array}{l}\text { Unadjusted regression } \\
\text { coefficient }(95 \% \mathrm{CL})\end{array}$ & $\begin{array}{l}P \text { - } \\
\text { value }\end{array}$ & $\begin{array}{l}\text { Adjusted }^{a} \text { regression } \\
\text { coefficient }(95 \% \mathrm{CL})\end{array}$ & $\begin{array}{l}P \text { - } \\
\text { value }\end{array}$ \\
\hline$\overline{\mathrm{BMI}}$ & $1.21(1.06-1.37)$ & 0.000 & $1.48(0.45-1.72)$ & 0.000 & $0.86(0.79-0.93)$ & 0.000 & $0.72(0.60-0.79)$ & 0.000 \\
\hline Age & $0.19(0.07-0.30)$ & 0.000 & $0.18(0.10-0.24)$ & 0.040 & $0.09(0.03-0.15)$ & 0.000 & $0.09(0.04-0.12)$ & 0.000 \\
\hline PAL & $-0.89(-2.49--0.71)$ & 0.780 & $-0.49(-0.61--0.25)$ & 0.680 & $-0.80(-1.33--0.28)$ & 0.860 & $-0.22(-0.39--0.16)$ & 0.230 \\
\hline $\begin{array}{l}\text { Location } \\
\text { (ST/BT) }\end{array}$ & $6.43(3.31-9.54)$ & 0.000 & $2.04(1.23-3.21)$ & 0.540 & $4.30(2.93-5.66)$ & 0.000 & $1.92(1.03-2.61)$ & 0.000 \\
\hline$R^{2}$ & & & 0.681 & & & & 0.683 & \\
\hline
\end{tabular}

BMI Body mass index, PAL Physical activity level

$\mathrm{R}^{2}$ : explained variance

${ }^{\text {a }}$ Mutually adjusted for all other variables

The area under the ROC curves predict $\mathrm{BF} \%$ for obesity in men and women based on BMI. The AUCs to predict $\mathrm{BF} \%$ for obesity reached 0.94 ( 0.90 to 0.99 with $95 \%$ CL) in men, which corresponds to a BMI cut-off value of $24.5 \mathrm{~kg} / \mathrm{m}^{2}$ (97.4\% sensitivity and $64.0 \%$ specificity) $(p<0.000)$ (Fig. 2a). In women, the AUC obtained was 0.95 (0.91 to $0.9895 \%$ $\mathrm{CL})$, which correspond to a BMI cut-off value of $32.9 \mathrm{~kg} / \mathrm{m}^{2}$ (93.3\% sensitivity and $86.0 \%$ specificity) $(p<0.000)$ (Fig. $2 \mathrm{~b})$.

The conventional classification systems were highly specific for both sexes, but their sensitivity was very low for the females. However the proposed classification systems for both sexes had a high specificity and above average specificity.

With the use of the optimal BMI cut-off for the proposed classification system derived from ROC analysis, a truly obese male would be 0.98 times as likely as a truly normal-weight male to be classified as obese, whereas a truly normal-weight male would be only 0.70 times as likely to be classified as obese. For the females, the proposed classification system performed much worse, with positive and negative likelihood ratios of 0.91 and 0.89 , respectively as presented in Table 3.

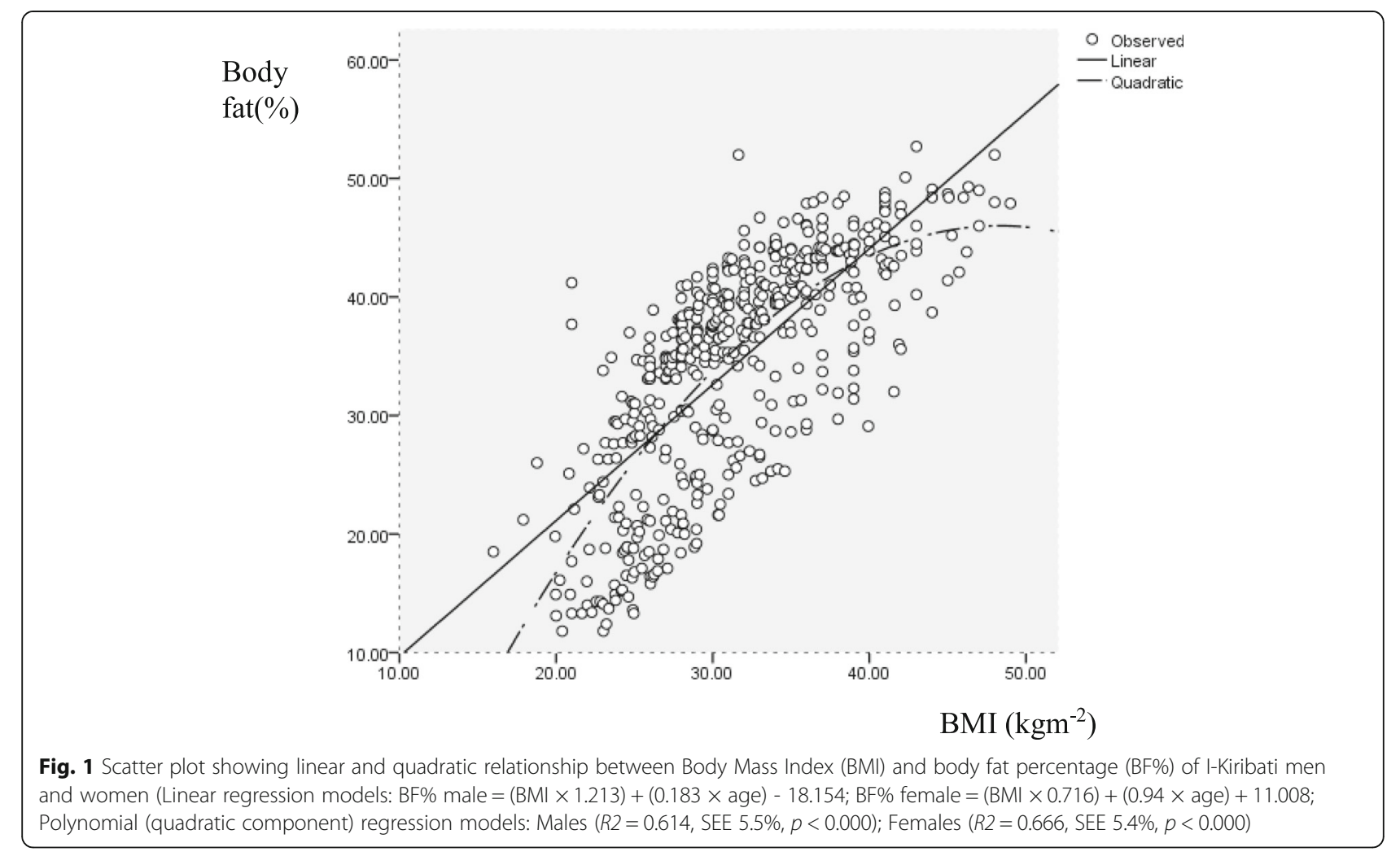




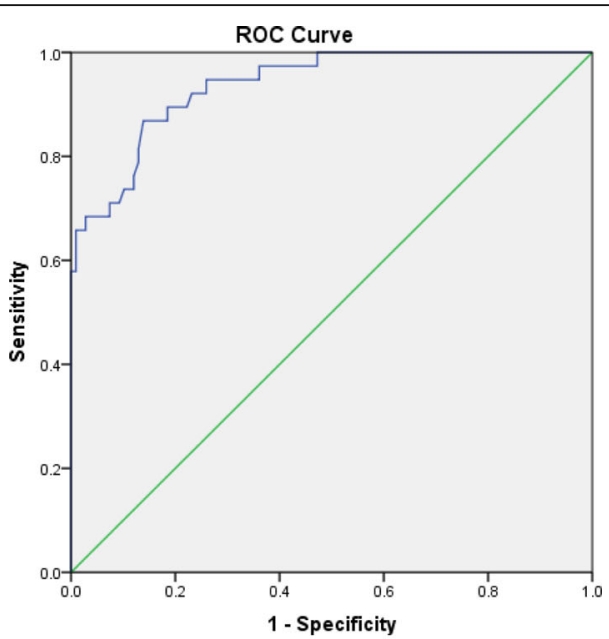

(a)

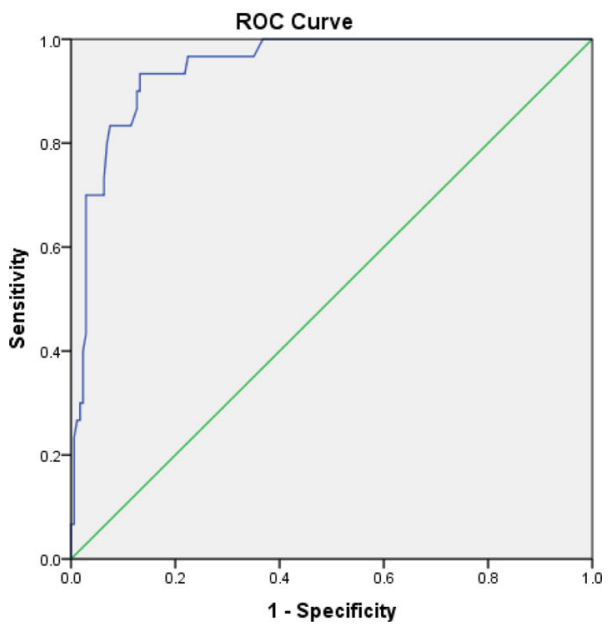

(b)
Area under curve (AUC)

for male $=0.938$,

$\mathrm{P}<0.000$
Area under curve (AUC) for female $=0.946, \mathrm{P}<0.000$

Fig. 2 ROC curve in males (a) and females (b) showing the performance of BMI in predicting BF\% in men and women

\section{Discussion}

The study was conducted in two atoll Islands that are reasonably representative of the Southern and Northern I-Kiribati population. The prevalence of obesity based on BMI and BF\% were 74.8 and $91.2 \%$ in ST, and 46.8 and $64.1 \%$ in BT, respectively. The mean obesity prevalence using the BMI classification was higher than the national average of $46 \%$ reported in 2016 [2], suggesting that the prevalence of obesity in Kiribati may be on the rise.
Urgent interventions are therefore needed to curb this increasingly important public health problem.

Our study confirmed a significant positive association between $\mathrm{BMI}$ and $\mathrm{BF} \%$, which has been demonstrated previously. A study by Rush and colleagues in New Zealand between 1990 and 2004 showed a positive significant relationship between BMI and BF\% among Europeans, Maori, Asian adults and Pacific Islanders [23]. Another study by Jackson et al. [24] among Caucasian adults from four

Table 3 Sensitivity and specificity for excess fatness for conventional and proposed BMI

\begin{tabular}{llllll}
\hline & Males & & \multicolumn{2}{l}{ Females } \\
\cline { 2 - 3 } & Conventional BMI & Proposed BMI & & Conventional BMI & 0.16 \\
Sensitivity & 0.28 & 0.64 & 0.96 & 0.93 \\
Specificity & 0.99 & 0.97 & 0.98 & 0.09 & 0.91 \\
Positive predictive value & 0.15 & 0.70 & 0.67 & 0.89 \\
Negative predictive value & 0.58 & & \\
\hline
\end{tabular}


clinical centres in US and Canada also showed a significant association between $\mathrm{BMI}$ and $\mathrm{BF} \%$. Also in agreement with previous studies, our study found that BF\% is greater in women [25] and in older age groups [26]. Furthermore, multiple regression analysis showed that sex and age affected the association between BMI and BF\%. Therefore, and based on other studies showing similar results $[15,27]$, this strongly supports that BMI values for predicting $\mathrm{BF} \%$ need to take into account gender and age (as well as ethnicity as discussed below).

Our study showed the relationship between BMI-BF\% was linear in nature but develops curvilinear towards higher $\mathrm{BF} \%$ values, based on a visual inspection (although a significantly better model fit using quadratic regression was not shown). This is supported by Meeuwsen et al. [16], but differs from results reported by Gallagher et al. [25], which showed a predominantly curvilinear association. Curvilinearity was mainly observed when participants had a BMI of $35 \mathrm{~kg} / \mathrm{m}^{2}$ or greater indicative of obesity [19]. The same was shown in a study by Jackson et al. [24], which showed that quadratic (curvilinear) effect became most pronounced at BMI levels of $\geq 35 \mathrm{~kg} / \mathrm{m}^{2}$. This was also the case for women, and less pronounced in men, in another body composition study from the USA in which half of the subjects had a BMI $>35 \mathrm{~kg} / \mathrm{m}^{2}$ [26].

The use of BMI cut-off values (based on studies of predominantly European and American Caucasians) to define overweight and obesity for populations with different ethnic backgrounds is controversial. In particular, there are several studies showing that the relationship between $\mathrm{BMI}$ and $\mathrm{BF} \%$ differs among ethnic groups; for example, studies with Indian [27], Indonesian [27], Tongan [28], Australian [29], Jamaican [30] and UK [31] populations have established that BMI represents different values of fat percentage for different populations. This is likely due to differences in energy balance and body build between ethnic groups [23, 27]. The present study showed the optimal cut-off points for predicting high BF\% among I-Kiribati people were $24.5 \mathrm{~kg} / \mathrm{m}^{2}$ for men and $32.9 \mathrm{~kg} / \mathrm{m}^{2}$ for women. These values vary considerably from the BMI cut-off value derived from American and European Caucasian populations which is $30 \mathrm{~kg} / \mathrm{m}^{2}$ for both genders [30]. Applying international BMI cut-points in Kiribati (and other countries in the Pacific) may therefore lead to severe misclassification, which may have significant public health implications, and this is why BMI cut-off points for obesity need to be population-specific [32]. In particular, if Kiribati-specific BMI cut-off were used, based on the results of this study, the prevalence estimates of obesity in Kiribati would be considerably greater than current estimate (which is already very high i.e. 46\% [7], further emphasising the need for the development of effective public health interventions to reduce the obesity epidemic in
Kiribati (and the pacific region more generally). It will also allow more valid comparisons with prevalence estimates of other countries and aid epidemiological research into the causes and mechanisms of obesity and related metabolic conditions in the Pacific region [33].

This study had several limitations. The sample was taken from two different atoll Islands of much disparity in access to health and education facilities and data may therefore not be generalizable to all I-Kiribati. The small population size is another limitation, but being the first of such study in the country and one of only very few in Pacific Island countries, it could serve as a reference. We were unable to control some of the BIA assessment imperatives as we depend on information given by the subjects e.g. despite insurances to the opposite, some may have engaged in vigorous activity in the $12 \mathrm{~h}$ prior to when measurement were taken.

\section{Conclusions}

Our results showed that there is high prevalence of obesity in the two atoll Islands of Kiribati using measures of both $\mathrm{BMI}$ and $\mathrm{BF} \%$. It also demonstrates that $\mathrm{BMI}$ is strongly associated with $\mathrm{BF} \%$ and that this was affected by age and gender. Therefore, our findings support controlling for age and gender when using BMI as a predictor of $\mathrm{BF} \%$. Based on our analyses we suggest that ethnic-specific BMI cut-points to define obesity for the population of Kiribati (i.e. $24.5 \mathrm{~kg} / \mathrm{m}^{2}$ for males and 32.9 $\mathrm{kg} / \mathrm{m}^{2}$ for females) may be more appropriate than the currently used international cut-points.

\section{Abbreviations}

BMI: Body mass index; BIA: Bioelectrical impedance analysis; NIR: Near infrared reactance; MRI: Magnetic resonance imaging; DEXA: Dual-energy Xray absorptiometry; WHO: World Health Organisation; BF: Body fat; PSID S: Pacific Small Island Developing State; PAL: Physical activity level

\section{Acknowledgements}

The authors wish to acknowledge Caritas Aotearoa (funding support), Director, Women Development Centre and the participants in Kiribati; and the Government of Kiribati.

\section{Authors' contributions}

PEE: Carried out all fieldwork, undertook primary data analysis and interpretation, prepared draft manuscripts and completed the revisions. NK: Involved in the conception and design of the study, technical input into the writing of the manuscript and the overall scientific management. BB: Was involved in the conception and design of the study and the overall scientific management. JD: Was involved in the conception and design of the study, technical input into the writing of the manuscript and the overall scientific management. SF: Was involved in the conception and design of the study as a PhD supervisor and expert on health in Pacific Islands. CW: Provided valuable technical input on interpretation of findings and content of the manuscript. All authors have read and approved the manuscript.

\section{Funding}

Partial financial support was obtained from Caritas New Zealand to support the data collection and played no role in the design of the study and collection, analysis, and interpretation of data and in writing the manuscript. 


\section{Availability of data and materials}

Data cannot be shared because it contains potentially identifying information of the human subjects and will only be shared when the patents related to this research are issued.

\section{Ethics approval and consent to participate}

Ethical approval was obtained from the Massey University Research Ethics Committee (No: 4000018013). We also obtained a research permit from Kiribati Immigration (RP No- 14/2017). Written consent was obtained from each participant

\section{Consent for publication}

Not applicable.

\section{Competing interests}

The authors declare that they have no competing interests.

\section{Author details}

'Department of Nutrition and Dietetics, University of Nigeria, Nsukka, Enugu State, Nigeria. ${ }^{2}$ School of Health Sciences, College of Health, Massey University, PO Box 756, Wellington 6140, New Zealand. ${ }^{3}$ Centre of Public Health Research, Massey University, PO Box 756, Wellington 6140, New Zealand. ${ }^{4}$ School of Sport, Exercise and Nutrition, College of Health, Massey University, Private Bag 102904, North Shore City, Auckland 0745, New Zealand.

Received: 1 October 2019 Accepted: 6 July 2020

Published online: 11 July 2020

\section{References}

1. WHO. Global status report on non-communicable diseases 2014. Geneva: World Health Organization; 2015.

2. WHO. Global status report on non-communicable diseases 2016. Geneva: World Health Organization; 2018.

3. Kirch PA. On the road of the winds: an archaeological history of the Pacific Islands before European contact. Berkeley: University of California Press: 2001. ISBN 978-0-520-92896-1.

4. NCD Risk Factor Collaboration. Obesity Prevalence Ranking. 2017. http:// ncdrisc.org/obesity-prevalence-ranking-ado.html.

5. World Atlas. Prevalence of obesity in Kiribati. 2020. https://knoema.com/ atlas/Kiribati/Female-obesity-prevalence.

6. Ziraba A, Fotso J, Ochako R. Overweight and obesity in urban Africa: a problem of the rich or the poor? BMC Public Health. 2009;9(1):465.

7. Eme P, Onuoha NO, Mbah OB. Fat-related anthropometric variables and regional patterns of body size and adiposity of adolescents in aba south LGA, Abia state, Nigeria. Food Nutr Bull. 2016;37(3):401-8.

8. Martins C, Morgan L, Truby H. A review of the effects of exercise on appetite regulation: an obesity perspective. Int J Obes. 2008;32(9):1337-47.

9. Akindele $\mathrm{MO}$, Phillips JS, Igumbor EU. The relationship between body fat percentage and body mass index in overweight and obese individuals in an urban African setting. J Public Health Afr. 2016;7:515.

10. World Health Organization. Obesity and overweight. Fact sheet N 311. 2012. http://www.who.int/mediacentre/factsheets/fs311/en/.

11. Bintvibok W, Cbaikittisilpa S, Panyakamlerd K, Jaisamrarn U, Taecbakraicbana N. Cut-off value of body fat in association with metabolic syndrome in Thai peri- and postmenopausal women. Climacteric. 2013;16:1-5.

12. Xu L, Cheng X, Wang J, Cao Q, Sato T, Wang M, Zhao X, Liang W. Comparisons of body-composition prediction accuracy: a study of 2 bioelectric impedance consumer devices in healthy Chinese persons using DXA and MRI as criteria methods. J Clin Densitometry. 2011;14(4):458-64.

13. Pietrobelli A, Rubiano F, St-Onge MP, Heymsfield SB. New bioimpedance analysis system: improved phenotyping with whole-body analysis. Eur J Clin Nutr. 2004;58(11):1479-84.

14. Sluyter JD, Schaaf D, Scragg RK, Plank LD. Prediction of fatness by standing 8-electrode bioimpedance: a multiethnic adolescent population. Obesity (Silver Spring). 2010;18(1):183-9.

15. Ranasinghe C, Gamage P, Katulanda P, Andraweera N, Thilakarathne S, Tharanga P. Relationship between body mass index (BMI) and body fat percentage, estimated by bioelectrical impedance, in a group of Sri Lankan adults: a cross sectional study. BMC Public Health. 2013;13(1):797.
16. Meeuwsen S, Horgan GW, Elia M. The relationship between BMI and percent body fat, measured by bioelectrical impedance, in a large adult sample is curvilinear and influenced by age and sex. Clin Nutr. 2010;29(5): $560-6$.

17. Flegal KM, Shepherd JA, Looker AC, Graubard BI, Borrud LG, Ogden CL, et al. Comparisons of percentage body fat, body mass index, waist circumference, and waist-stature ratio in adults. Am J Clin Nutr. 2009;89:500-8.

18. National Statistics Office. Population and Housing census; 2016. p. 3. www. mfed.gov.ki/statistics/documents/2015. Accessed 6 June 2018.

19. Jelliffe OB. The Assessment of Nutrition Status of the Community. Monograph Series No. 53. Geneva: World Health Organization; 1996. p. 50-84.

20. Gallagher D, Heymfield SB, Heo M, et al. Healthy percentage body fat ranges: an approach for developing guidelines based on body mass index. Am J Clin Nutr. 2000;72:694-701.

21. Moy KL, Scragg RK, McLean G, Carr H. The New Zealand physical activity questionnaires: validation by heart-rate monitoring in a multiethnic population. J Phys Act Health. 2008;5(s1):S45-61.

22. International Physical Activity Questionnaire Research Committee. Guidelines for data processing and analysis of the International Physical Activity Questionnaire (IPAQ)-short and long forms: IPAQ Research Committee; 2005. Available at http://www.ipaq.ki.se/scoring.pdf. Accessed 5 July 2019.

23. Rush EC, Freitas I, Plank LD. Body size, body composition and fat distribution: comparative analysis of European, Maori, Pacific Island and Asian Indian adults. Br J Nutr. 2009;102(4):632-41.

24. Jackson AS, Stanforth PR, Gagnon J, Rankinen T, Leon AS, Rao DC, Skinner JS, Bouchard C, Wilmore JH. The effect of sex, age and race on estimating percentage body fat from body mass index: the heritage family study. Int J Obes Relat Metab Disord. 2002;26(6):789-96.

25. Gallagher D, Visser M, Sepulveda D, Pierson RN, Harris T, Heymsfield SB. How useful is body mass index for comparison of body fatness across age, sex, and ethnic groups? Am J Epidemiol. 1996;143:228-39.

26. Adams TD, Heath EM, LaMonte MJ, Gress RE, Pendleton R, Strong M, Smith SC, Hunt SC. The relationship between body mass index and per cent body fat in the severely obese. Diabetes Obes Metab. 2007;9(4):498-505.

27. Deurenberg P, Yap M, Van Staveren WA. Body mass index and percent body fat: a meta analysis among different ethnic groups. Int J Obes. 1998 Dec;22(12):1164

28. Craig P, Colagiuri S, Hussain Z, Palu T. Identifying cut-points in anthropometric indexes for predicting previously undiagnosed diabetes and cardiovascular risk factors in the Tongan population. Obes Res Clin Pract. 2007;1:17-25.

29. Piers LS, Rowley KG, Soares MJ, O'Dea K. Relation of adiposity and body fat distribution to body mass index in Australians of aboriginal and European ancestry. Eur J Clin Nutr. 2003;57:956-63.

30. Luke A, Durazo-Arvizu R, Rotimi C, Prewitt TE, Forrester T, Wilks R, Ogunbiyi OJ, Schoeller DA, McGee D, Cooper RS. Relation between body mass index and body fat in black population samples from Nigeria, Jamaica, and the United States. Am J Epidemiol. 1997;145(7):620-8.

31. Bodicoat DH, Gray LJ, Henson J, Webb D, Guru A, Misra A, et al. Body mass index and waist circumference cut-points in multi-ethnic populations from the UK and India: the ADDITION-Leicester, Jaipur Heart Watch and New Delhi Cross-Sectional Studies. PLoS One. 2014;9(3):e90813.

32. Razak F, Anand SS, Shannon H, et al. Defining obesity cut points in a multiethnic population. Circulation. 2007;115:2111-8.

33. WHO Expert Consultation. Appropriate body-mass index for Asian populations and its implications for policy and intervention strategies. Lancet. 2004;363:157-63.

\section{Publisher's Note}

Springer Nature remains neutral with regard to jurisdictional claims in published maps and institutional affiliations. 